\title{
The effects of maternal eating on fetal nonstress test reactivity
}

\author{
JAMES W. HOLE, D.O. \\ Trenton, Michigan
}

Studies on the effect of recent ingestion of a meal or glucose on fetal activity as shown in the nonstress test (NST) have yielded conflicting results, and this study aimed to clarify the issue. Sixty women with high-risk pregnancies underwent 140 NSTs, and the time since last meal ingestion was recorded for each test. The relationship between the postprandial state and NST results could not be evaluated fully, because the nonreactive test rate was only 3 percent. However, statistical analysis showed trends suggesting a relationship between the number of hours since eating and NST reactivity with and without stimulation. These results may be influenced also by gestational age.

Antepartum fetal heart monitoring is widely accepted as a method for evaluating fetal well-being. Two commonly used testing procedures are the nonstress test (NST) and the contraction stress test (CST). In the NST, fetal heart rate accelerations associated with fetal movement correlate well with good fetal outcome. The absence of accelerations may be an indication of possible fetal compromise, but a nonreactive test is not as accurate in predicting poor outcome as the reactive test is in predicting fetal well-being. The CST often is used for additional evaluation of a fetus with a nonreactive NST. ${ }^{1}$ The presence of repetitive late decelerations with uterine contractions (a positive CST) is a more specific indicator of fetal compromise than is a nonreactive NST. However, the CST has several disadvantages and limitations: The test is more timeconsuming, is more expensive, requires closer nursing and physician supervision, carries a risk of contraction abnormalities such as tetany, and is contraindicated in patients with conditions such as placenta previa, premature labor, polyhydramnios, multiple gestation, or premature rupture of membranes. ${ }^{2,3}$ It would seem better, therefore, to avoid the necessity of performing a CST by eliminating the false-positive nonreactive NST. The best way to do this is by performing the NST under optimal circumstances.

Many conditions during the test period (for example, smoking, medication, time of day, and maternal fasting) have been evaluated to assess their influence on fetal heart rate testing. One of the factors of great interest is the time between the last maternal meal and test performance, and many studies have investigated this. A study in which patients were given an intravenous glucose solution and then monitored with real-time ultrasonography showed a significant increase in fetal movement 60 minutes after administration. ${ }^{4}$ In that study, peak glucose concentrations occurred a few minutes after administration, but peak fetal activity did not occur until after 60 minutes. An investigation to determine fetal activity after oral administration of glucose showed a statistically significant increase in fetal activity during a 30 minute period after ingestion. This study also found no correlation between absolute maternal glucose levels and fetal activities. ${ }^{5}$

In contrast, a widely quoted study found no association between a recent meal or fasting state and the result of the NST. ${ }^{6}$ A very ambitious study using continuous real-time ultrasonography for periods of 24 hours found that gross fetal body movements were not influenced by maternal meals or glucose concentrations. Peak fetal activity was between 2100 to 0100 hours, and periods of absence of gross fetal body movements lasted as long as 75 minutes. ${ }^{7}$ Other studies examining maternal 
glucose levels and maternal postprandial state also have found no relationship to fetal activity. 8,9

Because of the conflicting data in the literature, NST protocols differ among hospitals or clinics. Some include an oral glucose load or specific postprandial state, whereas others list no specific time or state for performance of the test. ${ }^{10,11}$ Because of the lack of consensus, this study was undertaken in an attempt to define any relationship between the maternal postprandial time and reactivity.

\section{Method}

Sixty women undergoing antenatal testing for high-risk pregnancies were selected at random and included in the study. The indications for testing included postdatism, hypertensive disorders of pregnancy, suspected intrauterine growth retardation, previous stillbirth, decreased fetal movement, and diabetes mellitus. Prior to each test, the number of hours since the patient had last eaten was recorded. Gestational age was evaluated by the obstetric resident in charge of testing.

The tests were performed with the patient in the semi-Fowler's position. Fetal movements were recorded on the monitor tracing if they were perceived by the patient or palpated by the nurse. Fetal heart tones were recorded by Doppler ultrasonography. If the initial 20 -minute test period was nonreactive, mild manual uterine stimulation was performed for 1 minute, and the test was continued for a further 20 minutes. Each test was performed under identical conditions in the same testing suite. The results of all NSTs were interpreted by the resident in charge of testing.

The NST was considered reactive if there were two fetal heart rate accelerations of 15 beats per minute lasting for 15 seconds, and if these were associated with a recorded fetal movement during either 20 -minute test period. The NST was considered nonreactive if there were fewer than two movements with the fetal heart rate criteria during the total test period. A test was considered unsatisfactory if monitoring did not allow adequate assessment of either fetal movement or fetal heart rate. If any NST results were interpreted as nonreactive, that test was followed by a CST (or biophysical profile if there were contraindications to, or an unsatisfactory, CST).

Statistical analysis was performed by the $\mathrm{G}^{2}$ test (likelihood ratio test). ${ }^{12}$

\section{Results}

The 60 subjects' ages ranged from 20 to 34 years; gestational ages ranged from 30 to 42 weeks. They underwent a total of 140 NSTs. The results were tabulated for analysis using one test for each patient as well as all tests performed (with the patients having serial NSTs as clinically necessary).

For the analysis, the observational data were divided into two groups: First, according to gestational age (30-36 weeks and 37-42 weeks); and, second, the period of time since eating $(0-2$ hours, 2-4 hours, and more than 4 hours). The results for both groups of tests are shown in Tables 1 and 2, respectively. As can be seen, no nonreactive NSTs were included in the tables. There were no nonreactive NSTs in the 30-36 weeks' groups, only 2 nonreactive NSTs in the $37-42$ weeks group (1 test/ patient group), and only 4 nonreactive NSTs were in the 37-42 weeks' groups (all tests performed). Such small numbers could result in a skewed analysis.

The data on hours since eating, gestational age, and reactivity with and without stimulation are analyzed statistically in Tables 3 and 4 . The $p$ values are low enough for both test groupings to indicate that both the number of hours since eating and gestational age affect reactivity. Further, they show that the effect of the number of hours since eating on reactivity appears to differ for the different gestational ages. For both test groupings (one test per patient and all tests), it may be that the number of hours since eating is a more useful

\begin{tabular}{|c|c|c|c|c|}
\hline \multirow[b]{2}{*}{$\begin{array}{l}\text { Gestational } \\
\text { age } \\
\text { (weeks) }\end{array}$} & \multirow[b]{2}{*}{$\begin{array}{l}\text { Hours } \\
\text { since } \\
\text { eating }\end{array}$} & \multicolumn{3}{|c|}{ Reactive NSTs } \\
\hline & & $\begin{array}{c}\text { With } \\
\text { stimulation } \\
\text { (no.) }\end{array}$ & $\begin{array}{c}\text { Without } \\
\text { stimulation } \\
\text { (no.) }\end{array}$ & $\begin{array}{l}\text { Total } \\
\text { (no.) }\end{array}$ \\
\hline \multirow{3}{*}{$30-36$} & $0-2$ & 2 & 12 & 14 \\
\hline & $2-4$ & 4 & 0 & 4 \\
\hline & $4+$ & 0 & 6 & 6 \\
\hline \multirow[t]{2}{*}{ Total } & & 6 & 18 & 24 \\
\hline & $0-2$ & 8 & 8 & 16 \\
\hline \multirow[t]{2}{*}{$37-42$} & $2-4$ & 2 & 10 & 12 \\
\hline & $4+$ & 0 & 6 & 6 \\
\hline Total & & 10 & $\overline{24}$ & $\overline{34}$ \\
\hline
\end{tabular}




\begin{tabular}{|c|c|c|c|c|}
\hline \multirow[b]{2}{*}{$\begin{array}{l}\text { Gestational } \\
\text { age } \\
\text { (weeks) }\end{array}$} & \multirow[b]{2}{*}{$\begin{array}{c}\text { Hours } \\
\text { since } \\
\text { eating }\end{array}$} & \multicolumn{3}{|c|}{ Reactive NSTs } \\
\hline & & $\begin{array}{l}\text { With } \\
\text { stimulation } \\
\text { (no.) }\end{array}$ & $\begin{array}{c}\text { Without } \\
\text { stimulation } \\
\text { (no.) }\end{array}$ & $\begin{array}{l}\text { Total } \\
\text { (no.) }\end{array}$ \\
\hline \multirow{3}{*}{$30-36$} & $0-2$ & 6 & 36 & 42 \\
\hline & $2-4$ & 6 & 4 & 10 \\
\hline & $4+$ & 0 & $\underline{10}$ & $\underline{10}$ \\
\hline \multirow[t]{2}{*}{ Total } & & 12 & 50 & 62 \\
\hline & $0-2$ & 12 & 38 & 50 \\
\hline \multirow[t]{2}{*}{$37-42$} & $2-4$ & 4 & 12 & 16 \\
\hline & $4+$ & 2 & 6 & 8 \\
\hline Total & & $\overline{18}$ & $\overline{56}$ & $\overline{74}$ \\
\hline
\end{tabular}

predictor of reactivity than gestational age. It can be seen that the results and $p$ values for the test groupings differ.

The results from the estimate of log-linear parameters examining the effect of hours since eating on reactivity are shown in Tables 5 and 6 . The results for the test groupings differ in that, for the one-test-per-patient group, those patients who ate $0-2$ hours prior to the test were likely to be reactive without stimulation, while those who ate more than 4 hours prior to the test were likely to need stimulation (the likelihood for subjects in the 2-4 hour range was intermediate). For the all-tests grouping, subjects who ate within $0-2$ hours of or more than 4 hours before the test all were likely to have reactive tests without stimulation. Those who ate within 2-4 hours of the test were more likely to need stimulation.

\section{Discussion}

The aim of this study was to clarify whether eating prior to an NST has an effect on its outcome. An answer to the question could lead to recommendations for an NST testing protocol that might result in fewer false-positive results (nonreactive NSTs) and prevent the need for a further test, such as the CST, which is more expensive, time consuming, and sometimes contraindicated.

This study, however, yielded a nonreactive NST rate of only about 3 percent. This rate is somewhat lower than others reported, which range from 12 to 34 percent., ${ }^{1,6,9}$ Because so few nonreactive NSTs were obtained, the relationship between postprandial state and reactivity could not be evaluated fully. However, trends in the analysis suggest that there is a relationship between the number of hours since eating and NST reactivity with and without stimulation. It is suggested further that gestational age also may influence these results. Manual stimulation should be avoided in some situations (for example, premature labor or premature rupture of membranes.)
TABLE $3 . \mathrm{G}^{2}$ DATA COMPARING EFFECT OF HOURS SINCE EATING (H) AND GESTATIONAL AGE (G) ON NST REACTIVITY (R), ON THE BASIS OF ONE TEST PER PATIENT.

\begin{tabular}{|lccc|}
\hline & $d f$ & $G^{2}$ & $p$ \\
\hline HG,R & 5 & 23.85 & .0002 \\
HG,RG & 4 & 23.71 & .0001 \\
HG,RH & 2 & 14.88 & .0006 \\
HG,RG,RH & 1 & 14.87 & .0001 \\
\hline
\end{tabular}

TABLE 4. $\mathrm{G}^{2}$ DATA COMPARING EFFECT OF HOURS SINCE EATING (H) AND GESTATIONAL AGE (G) ON NST REACTIVITY (R), ON THE BASIS OF ALL TESTS PERFORMED.

\begin{tabular}{|lcrl|}
\hline & $d f$ & $\mathrm{G}^{2}$ & $p$ \\
\hline HG,R & 5 & 13.51 & .019 \\
HG,RG & 4 & 13.02 & .0112 \\
HG,RH & 3 & 8.15 & .0430 \\
HG,RG,RH & 2 & 7.90 & .0193 \\
\hline
\end{tabular}

\begin{tabular}{|c|c|c|}
\hline \multirow{3}{*}{$\begin{array}{l}\text { Hours } \\
\text { since } \\
\text { eating }\end{array}$} & \multirow{2}{*}{\multicolumn{2}{|c|}{ Reactive NSTs }} \\
\hline & & \\
\hline & $\begin{array}{c}\text { With } \\
\text { stimulation }\end{array}$ & $\begin{array}{c}\text { Without } \\
\text { stimulation }\end{array}$ \\
\hline $0-2$ & -0.091 & 0.091 \\
\hline $2-4$ & 0.000 & 0.000 \\
\hline $4+$ & 0.091 & -0.091 \\
\hline
\end{tabular}

TABLE 6. ESTIMATES OF LOG-LINEAR PARAMETERS EXAMINING EFFECT OF HOURS SINCE EATING ON NST REACTIVITY WITH AND WITHOUT STIMULATION, ON THE BASIS OF ALL TESTS PERFORMED.

\begin{tabular}{|lcc|}
\hline \multirow{2}{*}{$\begin{array}{l}\text { Hours } \\
\text { since } \\
\text { eating }\end{array}$} & \multicolumn{2}{c|}{ Reactive NSTs } \\
\cline { 2 - 3 } & $\begin{array}{c}\text { With } \\
\text { stimulation }\end{array}$ & $\begin{array}{c}\text { Without } \\
\text { stimulation }\end{array}$ \\
\hline $0-2$ & -0.046 & 0.046 \\
$2-4$ & 0.426 & -0.426 \\
$4+$ & -0.379 & 0.379 \\
\hline
\end{tabular}

Data from the estimate of log-linear parameters show that subjects who ate within 2 hours of the test were more likely to have reactive test results without stimulation. Also, in the one-test-per-patient group, subjects who ate more than 4 hours prior to the test were more likely to need stimulation. 
A surprising finding of the analysis was that the results and trends in the one-test-per-patient group differed somewhat from those in the all-tests-performed group. It seems logical that serial NSTs on the same patient would yield different results, since they are performed at different times and at different gestational ages. However, since the differences were between results of the two test groups, it is suggested that multiple tests on the same patient may influence later test data. For example, a high-risk patient whose fetus has a normal central nervous system and whose utero-placental-fetal unit is intact is likely to have reactive NSTs and, therefore, multiple reactive tests as the protocol continues. A patient with a compromised fetal central nervous system or utero-placentalfetal unit will have a nonreactive NST earlier and will be removed from the testing protocol as the appropriate intervention occurs. As a result, the multiple test results are skewed toward the reactive NSTs.

\section{Conclusion}

The trend suggested by the results of this study have obvious clinical implications. Instructing patients to eat within the 2 hours prior to the test could increase the likelihood of obtaining reactivity without stimulation. This would decrease testing time and nurse participation (factors that can translate into lower costs). It also could prevent the need for manual stimulation in situations where it should be avoided, such as in premature labor or premature rupture of membranes.

Many of the trends found in this study would be clarified further by a much larger sample. It would be of particular interest, if enough nonreactive NSTs were obtained, to examine whether eating within 2 hours of the NST not only increases the possibility of the test being reactive without stimulation but possibly decreases the percentage of nonreactive tests.

1. Nochimson, D.J., et al.: The nonstress test. Obstet Gynecol 51:419-21, Apr 78

2. Evertson, L.R., et al.: Antepartum fetal heart rate testing. I. Evolution of the nonstress test. Am J Obstet Gynecol 133:29-33, 1 Jan 79

3. Ingardia, C.J., et al.: Prognostic components of the nonreactive nonstress test. Obstet Gynecol 56:305-10, Sep 80

4. Gelman, S.R., et al.: Fetal movements and ultrasound. Effect of maternal intravenous glucose administration. Am J Obstet Gynecol 137:459-61, 15 Jun 80

5. Miller, F.C., Skiba, H., and Klapholz, H.: The effect of maternal blood sugar levels on fetal activity. Obstet Gynecol 52:662-5, Dec 78

6. Rayburn, W.F., Motley, M.E., and Zuspan, F.P.: Conditions affecting nonstress test results. Obstet Gynecol 59:490-3, Apr 82

7. Patrick J., et al.: Patterns of gross fetal body movements over 24-hour observation intervals during the last 10 weeks of pregnancy. Am J Obstet Gynecol 142:363-71, 15 Feb 82

8. Phelan, J.P., Kester, R., and Labudovich, M.L.: Nonstress test and maternal serum glucose determinations. Obstet Gynecol 60:437-9, Oct 82 9. Druzin, M.L., and Foodim, J.: Effect of maternal glucose ingestion compared with maternal water ingestion on the nonstress test. Obstet Gynecol 67:425-6, Mar 86

10. Devoe, L.D., et al.: Nonstress test. Dimensions of normal reactivity. Obstet Gynecol 66:617-20, Nov 85

11. Rayburn, W.F., and Lavin, J.P.: Obstetrics for the house officer. Williams \& Wilkins, Baltimore, 1984

12. Fienberg, S.: The analysis of cross-classified categorical data. MIT Press, Cambridge, Massachusetts, 1983

Dr. Hole is a resident in obstetrics and gynecology at Riverside Osteopathic Hospital, Trenton, Michigan. Dr. David Wolf is chairman of the Department of Obstetrics and Gynecology and residency trainer, Riverside Osteopathic Hospital.

Dr. Hole, Riverside Osteopathic Hospital, 150 Truax Street, Trenton, Michigan, 48183. 